\section{Whales' Waterloo}

Science, it seems, has once again failed the sperm whale. Among other issues, the annual meeting of the International Whaling Commission (IWC), which convenes this week in Brighton, must decide on sperm whale catch limits. Quite how it will do so is not at all clear. The Scientific Committee of IWC, which met two weeks before the main commission, has, as last year, failed to make a recommendation.

Indecision continues to cast a cloud over the sperm whale. At a special meeting in March (Nature 1 April, p.383) the Scientific Committee, using the computer model developed by the International Institute of Environment and Development (IIED) and supported by all but the Japanese scientists, estimated the number of exploitable whales at around 200,000 . The analysis indicated that even with a zero catch, stocks would continue to decline. The Japanese presented their own computer model and pushed for a minimum quota of 890. A decision on catch limits was deferred to this week's annual meeting.

The recent meeting of the Scientific Committee produced a few surprises. A majority of the committee agreed that the IIED model estimate of population size had been too optimistic and that the population continues to decline. The Japanese did not re-present their earlier model but put forward a modification of the IIED model indicating that earlier population estimates were low.

In view of the Japanese dissent, the Scientific Committee was unable to recommend a catch limit or to classify the stock. Because of the disagreement on the state of the sperm whale stock it is difficult to assess whether a catch of $\mathbf{8 9 0}$ could be sustained without taking a serious toll on the population. The buck has now been firmly passed back to the IWC delegates. A political trade-off must now be made. The sperm whale is not the species in greatest danger of extinction. With the conservationist countries determined to stand firm and press for a total ban, some clever manoeuvring is now called for if IWC is to avoid even greater schism.

Jane Wynn

\section{Badger gassing}

\section{Ferrets stand in}

The study which earlier in the month precipitated the British government's abandonment of the policy of gassing badgers appears to have provided the most detailed information so far of the mortality of ferrets exposed to hydrogen cyanide. A total of 177 female ferrets were exposed to hydrogen cyanide in the course of the study, but only four badgers were thus used because of their scarcity.
The issue of gassing badgers with cyanide has been contentious since 1975 , when the Ministry of Agriculture, Fisheries and Food began gassing badgers suspected of being carriers of bovine tuberculosis. The practice was suspended towards the end of 1979 after complaints from conservationists and wildlife organizations that it was unnecessary, inhumane and ineffectual, but resumed in October 1980 after a report from Lord Zuckerman that confirmed that badgers can be reservoirs for bovine tuberculosis, a conclusion disputed by some conservationists.

The Zuckerman report on badgers also pointed to the lack of experimental evidence of the effects of cyanide on badgers, when the study commissioned by the agriculture ministry from the Chemical Defence Establishment at Porton Down (not to be confused with the now-civil microbiology establishment at the same place). The report of that study, by anonymous officials at the establishment, was published last week.

The first objective of the study was to establish a kind of dose-response relationship for mortality among ferrets, chosen as

IMAGE
UNAVAILABLE
FOR
COPYRIGHT
REASONS

experimental animals on the recommendation of Lord Zuckerman. One of the defects of the study is that the sample of ferrets (obtained from a commercial supplier) appeared to consist of two groups differing in body weight. The animals were exposed in groups of three to various concentrations for periods of 1,5 and 25 minutes. Nothing is said in the report of the age of the animals, which had nevertheless been bred especially for the study.

The exposure of ferrets is measured as the product of the concentration of cyanide in the air and the time in minutes for which the ferrets breathed it. The ferret part of the study was used so as to estimate the likely lethal doses for badgers, fourteen times heavier than ferrets on the average, by means of the rule that the exposure required to produce a specified mortality is proportional to (body-weight) ${ }^{0.7}$.

On this basis, the estimated exposures to cyanide needed to kill 90 per cent of badgers after times of 1,5 and 25 minutes are $2,000,5,000$ and $5,500 \mathrm{mg} \mathrm{min} \mathrm{m}^{-3}$ respectively. The report says that these "crude" estimates are supported by the experiments in which four badgers were exposed to cyanide gas. The only badger that died was exposed to $6,560 \mathrm{mg} \mathrm{min}^{-3}$ for 17 minutes; the other three have been returned to the wildlife park from which they came.

The government's decision to abandon the use of cyanide against badgers has been prompted by the knowledge that concentrations of cyanide in the tunnels of badger setts rarely approaches that needed to kill them within minutes, if at all. Its problem now is whether it can devise an alternative humane way of killing badgers - and do so quickly. Conservation interests will be able to exploit a prolonged hiatus in the control programme to reopen the question of its necessity. The use of carbon monoxide and nerve gases as alternative methods of control was ruled out in the Zuckerman report as being respectively ineffectual and "too dangerous"'.

\section{British academic industry \\ Prize incentives}

"We realize that we're just a football. We're here to be kicked by both sides." Thus a spokesman for the British Technology Group (BTG) on the group's present interest - the marriage of industry and academic science to put high technology on the market. In its latest venture, an academic enterprise competition, BTG hopes to encourage academics to don the entrepreneurial cap. Last week, Patrick Jenkin, Secretary of State for Industry, handed out cheques totalling $£ 230,000$ to twelve winning entries.

The academic enterprise competition, E originally sponsored by the National Research Development Corporation (now part of BTG), was open to science researchers from British institutions of higher education who had set up, or planned to set up, a business based on their research work. At the award ceremony, enthusiasm ran high. Sir Alastair Pilkington, chairman of the panel of five judges, declared "We would like to see a large number of academics become millionaires every year'". Patrick Jenkin described the occasion as one of "unique importance"'. The competition was all about the partnership between education and industry and aimed to dispel the feeling that "somehow for an academic to go into industry is disreputable". He issued a warning that the government's position was firmly on the sidelines. Public funds were but the seeds of support.

Professor W.A. Gambling of the University of Southampton, whose company York Technology Ltd took the top

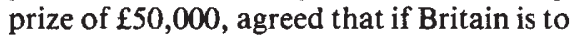
"seize the juicy plum" and commercialize high technology, higher education must play its part. But he added that the main occupation of the academic remains teaching and research.

Although legislation has yet to be passed, the National Research Develop- 